\title{
The Challenges of Predicting Structural Performance in Fires
}

\author{
ANDY BUCHANAN \\ Department of Civil Engineering \\ University of Canterbury, \\ Christchurch, New Zealand
}

\begin{abstract}
This paper describes the challenges of predicting structural performance in fires, with a view to the past, the present and the future. Despite the huge advances in computational capability for both fire modelling and structural analysis, it remains very difficult to give accurate predictions of structural performance in a single building with a known fire. Most designers grapple with a known building and an unknown possible fire (or fires), and code writers valiantly attempt to give rules or guidelines for whole classes of unknown buildings which could be exposed to any kind of unknown fires.
\end{abstract}

KEYWORDS: structural design, fire performance, structural analysis

\section{WHERE HAVE WE COME FROM?}

Since 1666, the Great Fire of London has changed the way that cities considered fire safety. Since then there has been slow development for several centuries, with roughly similar approaches in different parts of the world. For structural fire engineering, the events of 9/11 2001 may be looked back on with a similar view in the future [1].

\section{Developments in the 20th century}

Over the past hundred years there have been a huge number of developments. There has been world-wide development of comprehensive building codes and fire codes, all initially based on a prescriptive model. Following the work of Ingberg in the USA, similar test methods were established for fire resistance testing in most countries of the world, leading to the acceptance of Fire Resistance Ratings (or Fire Endurance Ratings). All of this was done with very little underlying science, but it led to increased structural fire safety in buildings.

\section{Change in the last 30 years}

There have been numerous changes in the field of structural fire engineering in the last 30 years. Major changes include the following:

- Fire safety science has matured greatly (most importantly with post flashover fire models, following the pioneering work of Kawagoe in Japan).

- There have been great improvements in the understanding of structural behaviour under fire conditions, led by international pioneers including Ove Pettersson and Margaret Law.

- There has been a huge increase in computing capacity and the use of computer models, for both fire growth and structural analysis.

- The advances in structural analysis under ambient conditions have slowly been expanded into structural analysis under elevated temperatures due to fire conditions.

- Full scale fire tests (eg Cardington in UK and Williams Street in Australia) have provided fresh evidence on the excellent structural fire performance of well designed structures.

- There has been a gradual international shift from prescriptive codes (no calculations) to performancebased codes where any design can be accepted if the stated performance requirements are met.

- This has required much better science, and much more detailed calculation methods.

- European countries have collaborated to produce comprehensive fire sections for the Structural Eurocodes for all main structural materials.

- The 9/11 WTC collapse has provided an impetus for structural fire engineering research, development, and education, especially in the USA. 
These changes have led to improved outcomes, including much more predictable behaviour of buildings in fire, hence safer buildings for less cost, with many more changes still on the way. Recent changes are described by Milke [2].

\section{Some things never change}

We must remember that some things never change. These include the basic laws of nature, including the chemistry and physics of combustion, the laws of heat transfer, and the statics, dynamics, and equilibrium of structures to resist the forces of gravity.

Another thing which has not disappeared is the need for wise engineering judgement to be used in solving complex problems. The more difficult the problems and the more advanced the computational tools, the more we will need expert engineering judgement to help prepare the input, to interpret the output, and to come up with practical real-world solutions.

\section{WHY DO WE WANT TO PREDICT STRUCTURAL PERFORMANCE?}

\section{Different answers for different stakeholders:}

The stakeholders for structural fire safety follow a spectrum from the building owners to the designers, regulators, forensic investigators, researchers, manufacturers, and code writers. The owner and designer consider only one building at a time, whereas the code writers and manufacturers consider whole groups of buildings. These people want entirely different things, as shown in Table 1.

Table 1. Questions asked by different stakeholders.

\begin{tabular}{|l|l|l|}
\hline Which person & Which buildings & Question \\
\hline Building owner & My building & $\begin{array}{l}\text { Will it be safe? } \\
\text { Can I save some money? }\end{array}$ \\
\hline Designer & Single building & $\begin{array}{l}\text { What is the required level of code } \\
\text { compliance? }\end{array}$ \\
\hline Building regulator & Single building & Does it meet the code? \\
\hline Manufacturers & Many buildings & How can we sell more products? \\
\hline Code writers & Many buildings & How do we codify buildings of this type? \\
\hline Researchers & Many buildings & How clever are we? \\
\hline Forensic investigator & Single building & Why did it collapse? \\
\hline
\end{tabular}

Another way of looking at the stakeholders is to classify according to what is known and what is unknown, as shown in Table 2. The more that is unknown, the more difficult the exercise of prediction. Even in the case of a known building and a known fire, the World Trade Center investigation showed how complex the task can be, using state-of-the-art technology.

Table 2. Known and unknown buildings and fires.

\begin{tabular}{|l|l|l|l|}
\hline Which person & Which buildings & Building structure & Fire exposure \\
\hline Forensic investigator & Single building & Known & Known \\
\hline $\begin{array}{l}\text { Designer, } \\
\text { Building regulator }\end{array}$ & Single building & Known & Unknown \\
\hline $\begin{array}{l}\text { Code writers, } \\
\text { Researchers }\end{array}$ & $\begin{array}{l}\text { Many buildings of } \\
\text { this type }\end{array}$ & Unknown & Unknown \\
\hline
\end{tabular}

\section{What is the level of structural fire resistance required?}

The first question is whether the designer or regulator will allow the building to collapse. Prevention of structural collapse in a fire may be essential, important or totally unimportant, depending on the use of the building, the value of the building, and the activities of the building occupants. This hierarchy is codified in different ways in different countries. 
Many building codes allow design for structural collapse under certain conditions. If collapse is allowed, it is important to define the time of allowable collapse, which will be very different for different buildings. The most important criteria will be to ensure escape of all occupants and protection of fire fighters. Most building owners believe that they will never have a serious fire, so they are reluctant to engage in discussion with fire engineers during design of their new buildings .

\section{Do we rely on the sprinkler system or the fire brigade?}

These are big questions which have a huge impact on prediction of structural performance in fires. Fire brigade intervention can sometimes prevent growth to flashover, but this is unlikely because of the time for detection, alerting and travel to the building. An increasing number of major buildings have automatic fire sprinkler systems which will prevent flashover for $95 \%$ to $99 \%$ of likely fires. This creates a dilemma - if sprinklers operate as designed, no fire resistance is required, but there is always a low probability that sprinklers will not activate due to water supply failure or some other problem, in which case design for full burnout is necessary. For this reason it is difficult to justify a large reduction in the design fire load or heat release rate if sprinklers are installed, even though this is allowed by some codes. The best way of managing the small probability of sprinkler failure due to earthquake, maintenance, or poor design is a quantitative risk assessment, including the requirements of all stakeholders.

\section{What do the regulators want?}

The requirements of building regulators are very much dependant on the laws and rules under which they operate. In many parts of the world, fire design is still based on prescriptive codes which state how buildings are to be built. The language is - "do this, do that, don't ask any questions". The regulators are left with little or no alternative to ensuring that specified fire resistance ratings are provided for each major element of the building construction. Detailed calculations are not needed.

The international trend is towards performance-based codes which allow any design to be accepted if the stated performance requirements are met. This requires much better science and much better predictive tools as described later in this paper, but we can never get away from the application of engineering judgement.

Even in countries with performance-based codes, serious design efforts in predicting structural performance are only carried out for a small number of buildings. Such calculations are only being made in those places where there is one or more of the following drivers:

- The building owners believe that benefits in cost or aesthetics will result from a reduction in applied fire protection or other prescriptive requirements, while meeting the performance requirements of the code, OR

- A new form of construction is proposed for a very special building housing lots of people or valuable exhibits.

In either case it is essential that:

- $\quad$ Adequately qualified and respected fire engineering consultants are available to do the work, AND

- The performance-based codes allow alternative solutions to be offered, AND

- Trained regulators or rigorous peer review is available to check the performance-based design solution.

Case study - New Zealand

A performance-based fire code has been in use in New Zealand for 15 years. Some international reviewers have asked how well this has worked. A brief summary is that the new system initially worked well, with a small number of specialist fire engineers offering well-thought-out alternative designs. The new performance requirements resulted in a big shift from property protection to life safety. Some problems arose when poorly trained competitors ("cowboys with computers") entered the market, although those problems are now being addressed with new levels of peer review, and proposed new national standards for more formal prescription of design fires. 
Structural fire engineering in New Zealand has not grown significantly since the introduction of the performance-based code, mainly because of the shift in emphasis from property protection to life safety of occupants and fire-fighters. The performance requirements only require protection of other peoples' property, with building owners free to make their own decisions about protection of their own property. In addition to this, the passive fire resistance requirements in the Acceptable Solution ("deemed to satisfy" documents) have been dropped to very low levels which gives designers very little opportunity to offer savings to their clients by offering specific structural fire engineering design.

These developments in New Zealand are not necessarily the same in the rest of the world, but they illustrate some of the risks associated with performance-based design for structural fire safety.

\section{HOW DO WE PREDICT STRUCTURAL PERFORMANCE?}

The flow chart in Figure 1 will be used to describe many of the challenges of predicting structural fire performance. This has been expanded from an earlier chart by the author [3].

The good news is that the three calculation models in Figure 1 are essentially uncoupled. This allows them to be operated by different people on different computers at different times, if necessary. The thermal model and the structural model are usually integrated into one package, but the fire model usually remains separate.

The bad news is that almost every item in Figure 1 is changing with time, so each model must be run and re-run for several hours of fire exposure, which is often a major undertaking.

\section{The Structural Model}

The rest of this paper focuses on the structural model. To put the structural model into perspective, it is useful to compare structural analysis in fire with structural analysis and structural design under ambient conditions. Even with no changes in temperature (hence no thermal gradients, no thermal expansion or thermal contraction), the normal structural analysis of a large structure in ambient conditions is very complex, even under simple loading conditions such as static gravity loads. Things become more difficult under changing load conditions, such as seismic design for earthquake loading, or extreme wind engineering.

At extreme load levels it becomes essential to move beyond "working stress analysis" and the "serviceability limit state" into consideration of the "ultimate limit state" in order to predict large deformations and possible collapse. This requires assessment of non-linear material behaviour, ductile development of plastic hinges, and possible brittle response such as spalling of cover concrete.

For structural analysis during fire design, all the above problems apply, and more. A full time-history analysis is essential, with continual changes in the external and internal temperatures of materials, and calculation of the resulting thermal stresses. Thermal and mechanical properties of all the materials are changing as a result of temperature changes, and material behaviour moves from elastic to ductile, and to brittle for some materials. Creep deformations are often ignored at ambient temperatures, but they must be considered in fire design, either explicitly or implicitly, because creep can speed up at elevated temperatures, contributing to structural failure.

Detailed structural analysis under fire exposure is far more difficult than ambient temperature structural analysis under the normal range of loads encountered in day-to-day structural engineering. This means that only a small number of specialist practitioners are available. 


\section{Fixed input items:}

Input items which may change during the fire:

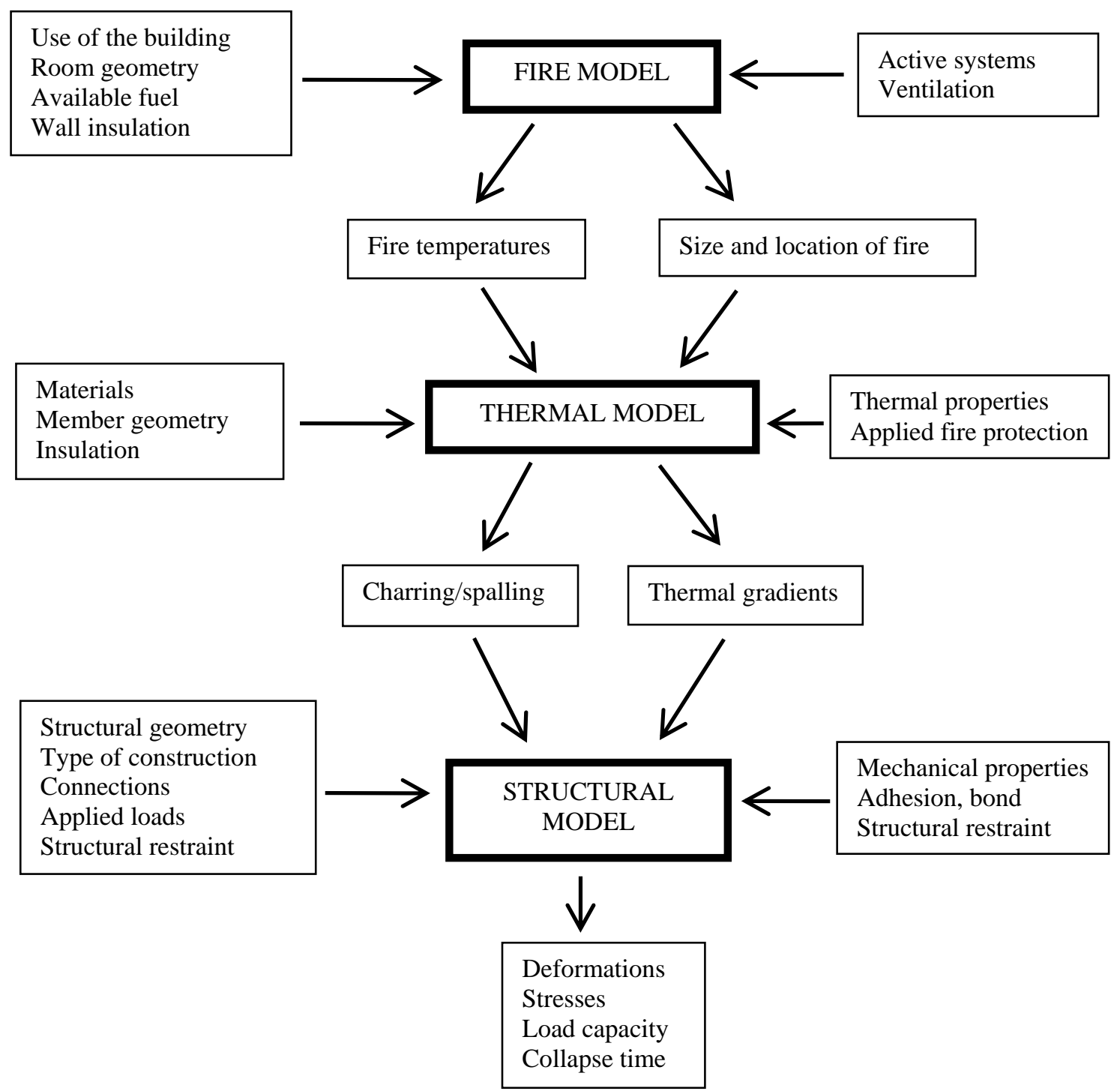

Fig. 1. Flow chart for predicting structural fire performance

\section{CHALLENGES OF PREDICTING STRUCTURAL PERFORMANCE}

The challenges of predicting structural performance are huge, and complex. There is a desire to keep things as simple as possible, so that traditional structural engineers can become involved in the process without too much additional learning. On the other hand, rapid growth in computing power is not greatly increasing the ability of designers to do improved analysis of structures in fire, because of a lack of accurate input information at all steps in the process shown in Figure 1. Prediction of structural fire performance is not a game for amateurs, because it is very easy to make mistakes and small mistakes can lead to very inaccurate or misleading results. 


\section{Hand calculations}

All of the steps in Figure 1 can be carried out by hand calculation, but often with less accuracy than available with computer analysis. Modern design codes such as the structural Eurocodes provide useful tools for hand analysis of most of these steps.

\section{Available software}

There is a wide choice of software available for predicting structural fire performance [4]. The two main classes of software are the general purpose structural analysis packages, and a smaller number of firededicated packages. The fire-dedicated packages have advantages of already including much of the temperature dependent material data and they will include certain assumptions about elevated temperature behaviour. When selecting software, it is important to look for transparency and good documentation, so the intelligent user can see what assumptions have been made, what data has been used for material properties and failure criteria, preferably all described in a comprehensive manual.

\section{How much time have we got to predict structural behaviour?}

It is a truism that in any computer analysis we can only have any two of three variables: fast, accurate, or inexpensive. The three options are

- $\quad$ fast and cheap - but inaccurate

- $\quad$ fast and accurate - but expensive

- $\quad$ accurate and cheap - but very slow

The available time is completely different for different situations. For one building during an emergency we have only minutes to predict the structural behaviour. In preliminary design we have hours or days. A full design can take weeks, a risk assessment may take months and a forensic study can continue for years, as shown in Table 3 . The accuracy of the prediction will vary accordingly.

Table 3. Time available for structural fire calculations.

\begin{tabular}{|l|l|}
\hline Operation & Time available \\
\hline Fire fighting emergency & Minutes \\
\hline Simple design & Days \\
\hline Complex design & Weeks \\
\hline Code writing & Months \\
\hline Forensic study & Years \\
\hline
\end{tabular}

\section{Limitations on input data:}

The limitations on input data depend on the objectives of the person making the prediction, as described above. There is not space to describe all the limitations on input data, so a few will be given as examples:

\section{Unknown fire}

The biggest unknown is usually the fire severity. The structural engineer knows almost nothing about the expected size or location or duration of the fire, especially if there is a large space where a post-flashover fire may be migrating with time. All fires must be considered through the growth, burning, and decay phases. It is often impossible to predict which parts of which elements will be exposed to which level of fire severity. The cooling phase of the fire is often ignored, especially in standard fire resistance testing and fire resistance calculations, but it may be the critical period for structural collapse of a real building. 


\section{Unknown end support conditions}

The end support conditions have a powerful effect on the fire resistance of even the most simple beam or slab. In the academic arena we try to bound the problem by using four extremes of support condition:
1. Pin-roller
(simply supported, no axial restraint)
2. Pin-pin
(pin supports, with axial restraint)
3. Fix-fix
(fully fixed at both ends, full axial restraint)
4. Fix-slide
(rotationally fixed at both ends, no axial restraint)

For supports incorporating axial restraint ( 2 and 3 above), it is very important to correctly model the height of the restraint relative to the main axis of the beam or the slab to get correct results. For real buildings, any one of these idealised conditions can be used, or an intermediate condition using additional elements to adjust the height of the restraint or springs to model flexible restraint conditions, depending on the actual building. Uncertainty is reduced if the whole structure is modelled.

\section{Unknown structural restraint}

The biggest structural unknown is often the degree of structural restraint provided by the surrounding structure. This is difficult to estimate for a known building, even if the size and area of the fire are known. It is much more difficult to estimate if the size and area of the expected fire are unknown. This problem can become almost impossible for a code writer attempting to make recommendations for a large group of building types exposed to unknown fires.

For example, consider a typical concrete slab made up of precast prestressed hollow-core concrete planks. Starting at the simplest level we can model just one plank on simple supports, and verify the result with a fire resistance test. To assess the effect of realistic restraint, we must do a lot more analysis. We start by adding more elements. The sequence of analysis may be as follows:

1. select and model one plank spanning between rigid supports (tested assembly with no end connection)

2. same again but with a selected end support connection.

3. several planks side-by side, spanning between rigid supports, no side beams

4. same again, except the rigid supports are replaced by simply supported end beams

5. $\quad$ same again, except the end beams have pinned (or fixed) end conditions

6. same again, except end beams are fixed to single storey columns with pinned bases

7. same again, except the columns are continuous multi-storey columns

8. same again, with side beams at both sides of the group of planks (need to determine support conditions between the last plank and the side beam)

9. same again, with an additional span of planks both ways beyond the end beams, to give continuous supports

10. same again, with an additional span of planks both ways beyond the side beams to give restraint from the surrounding cooler structure

We now end up with ten analysis options of increasing complexity, each more realistic than the previous one, leading to the shaded slab shown in the centre of Figure 2, in one floor of a simple multi-storey building. It can be seen that there are a multitude of structural options for only one type of flooring panel, even for a simple floor plan. Many of these restraint options can give very different results, yet only the first can be verified by a fire test.

The fire exposure has not yet been defined. The fire could be confined to just the shaded centre slab in Fig. 2, or it could be another single bay, or a combination of bays as the fire spreads. Even if the fire is contained to only affect one bay, the restraint conditions will be very different if the fire affected slab is the 
centre bay (shaded) or one of the outer bays or a corner bay. For an accurate analysis it is also necessary to know which beams and/or columns will be exposed to fire, and for how long.

This simplistic example shows how difficult it becomes to make recommendations for unknown fire exposure in an unknown building, even if the type of precast flooring system is known exactly. This difficulty was encountered by Chang [5] when attempting to make recommendations for precast concrete hollow-core units.

\section{Problems of scale}

Before making a structural analysis for fire exposure, it is extremely important to decide on the appropriate level of detail. For example, in the NIST analysis of the WTC collapse, the forensic structural engineers found it impossible to use one computer modelling scheme for the whole building including the details of connections at every level. They partially solved this problem by using the output from detailed analyses of one part of the structure as input to a less detailed analysis of the whole building [6].

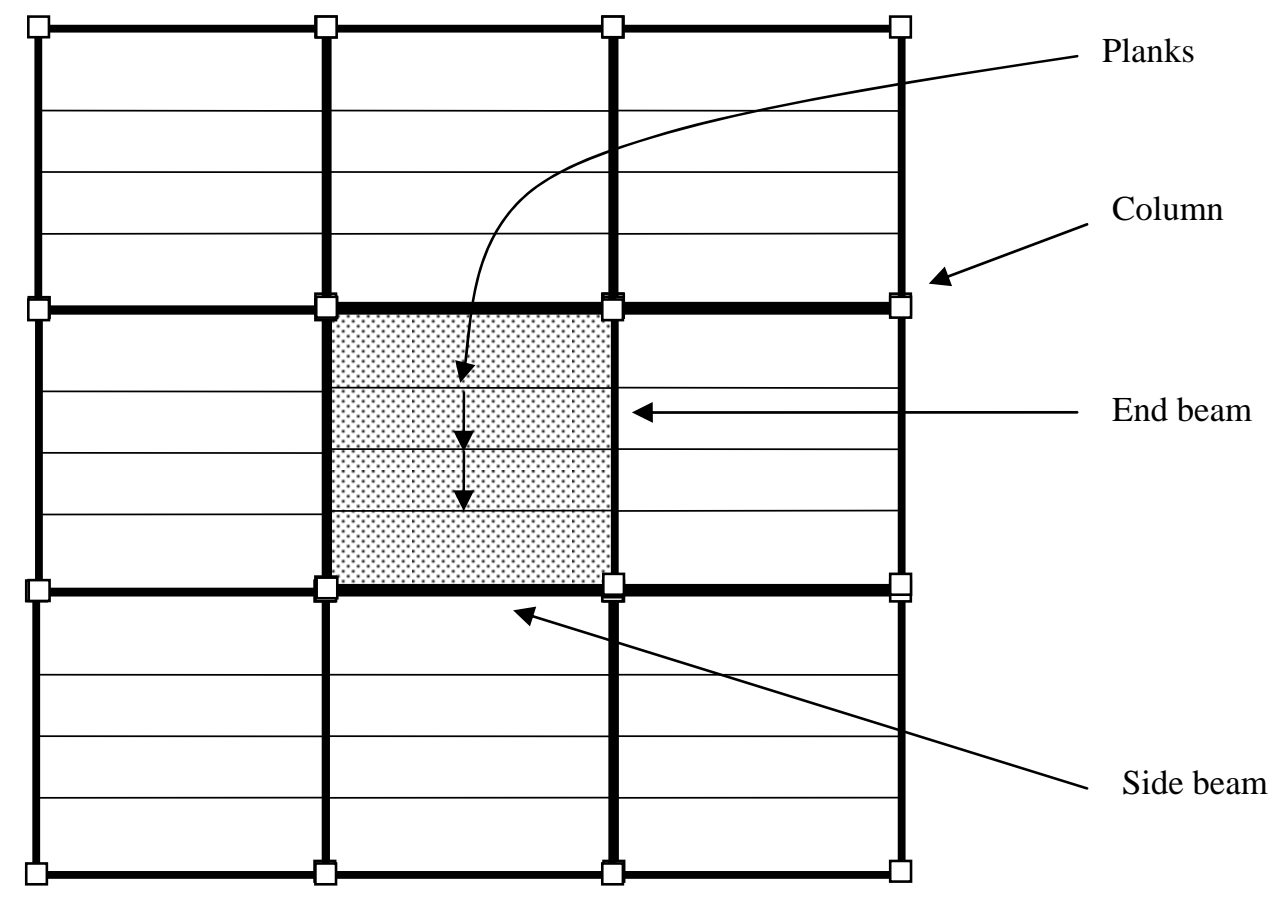

Fig. 2. Nine bay floor slab with beams and columns

It becomes clear that the more components which are added to the problem, the greater the number of assumptions which have to be made, about the materials of each component, their connections to each other, the degree of structural restraint, etc etc, before even starting to look at the fire exposure.

Another problem with detailed computer analysis is management of the vast quantity of output data. In addition, as the size of the computing exercise grows, it becomes more difficult for the overseeing structural engineer to carry out the intuitive peer review which is essential to ensure that the input and output actually make sense.

\section{Lack of verification}

Another problem with large scale computer predictions is the lack of verification of the models, at all the steps shown in Figure 1. Because fires most often occur when least expected, there is a lack of large scale test results for calibration and verification of the fire models and structural models. So called "full-scale" 
fire resistance tests were once considered suitable for this purpose, but they represent only a tiny part of a large building structure, and they never use exposure to realistic fires.

The international structural fire engineering community should be looking for more opportunities for realistic fire tests in actual buildings, perhaps using buildings scheduled for demolition.

\section{Consistent level of crudeness}

Whatever we do, we need to maintain a "consistent level of crudeness" [7]. There is no point in obtaining highly accurate data for one part of the analysis, with a level of accuracy out of balance with the crudeness of the least well defined part of the problem. This simple concept is often lost sight of, but needs to be kept in the mind of anyone attempting to carry out predictions of structural fire performance.

\section{Hierarchy of methods for predicting structural performance:}

As pointed out at this conference three years ago [4], there is a hierarchy of methods for predicting structural performance, as referred to in many modern codes. These are:

1. Experimental testing

2. Tabulated data

3. Simple calculation models

4. Advanced calculation models

Experimental tests are mostly done using standard fire resistance tests, which fortunately are similar throughout the world. Standard fire resistance test methods will not change dramatically because of the huge costs associated with any change. It is well known that standard fire resistance tests do not represent real fire exposure, but they remain useful for two reasons; firstly as a comparative method of comparing different fire resistive assemblies, and secondly for providing data for verifying computer models which can then be used for a far wider range of applications. It will be very useful if larger furnaces can be developed for research testing sub-assemblies of elements rather than just single elements at present. An important addition to standard fire resistance tests would be the continuation of load application and temperature measurement through the cooling phase.

The cooling period is extremely important, as buildings may lose half of their strength during the burning period of a fire and another half during the cooling phase [8]. During the cooling period the temperatures go down, the strength goes up, and the members try to get shorter due to thermal contraction, resulting in huge tensile forces which were never designed for, with the possibility of collapse.

Seismic designers have a similar hierarchy of tools with increasing complexity and increasing computing power required:

1. Prescriptive rules for construction of simple buildings

2. Calculation using equivalent static forces

3. Calculation using modal spectral analysis for a family of earthquakes

4. Calculation using time-history analysis for one specific earthquake

\section{Problems modelling structural materials:}

Different structural materials have very different properties, which need to be considered as part of any prediction of fire performance. The three main materials will be considered briefly:

\section{Steel}

Structural steel, like most metals, has high thermal conductivity, which can result in high temperatures for thin structural elements. Structural modelling is relatively straightforward because of ductile material behaviour in both tension and compression, although a large number of nodes are necessary to model 
possible problems of instability of very slender members [9]. A common unknown is the protective insulation which may be damaged or may fall off during a fire.

\section{Concrete}

Reinforced concrete has low thermal conductivity hence low internal temperatures, but it is a brittle material with zero tensile design strength (hence requiring steel reinforcing). One-dimensional beam elements in a reinforced concrete structure need only a simple 1-D failure criterion, but shell elements (in a slab for example) have a bi-directional stress field and it becomes very difficult to establish 2-D failure criteria for all possible cases, even without considering such difficult issues such as aggregate size and shape and cement properties at elevated temperatures. Bond and anchorage failures in reinforced or prestressed concrete structures are almost impossible to model at present. Another problem is the difficulty of predicting possible spalling of cover concrete due to high temperatures. Brittle fractures of concrete in complex stress fields can cause computational difficulties.

\section{Wood}

For timber structures, it is well known that exposed wood surfaces will burn, adding to the fire load, but large timber members have excellent behaviour due to the low thermal conductivity and a predictable charring rate. Structural members will have loss of cross section size due to charring. It is extremely difficult to model the thermal behaviour of wood if the mass transfer of water vapour is to be included, as this requires modelling evaporation and condensation of moisture within the wood cells. Because of this difficulty there is wide scatter in published data for thermal properties of wood. Mechanical properties are highly affected by the local moisture content of the wood material, making these also difficult to model. Because wood cannot be cast (like concrete) or welded (like steel), the connections are always very important, and the modelling is not easy [10].

Light steel structures and light timber structures are similar in that they both need some form of applied fire protection, and both will perform poorly if the protective material falls off during fire exposure.

\section{Computational problems}

Detailed computer analyses of complex structures often run into computational problems. When there are tens of thousands of nodes and finite elements which need to be brought into equilibrium at thousands of time steps, it is not unusual for computational difficulties at one highly stressed or cracked element to cause the computer program to terminate. This may be due to a local lack of convergence or some other computational problem which does not necessarily signal structural collapse in the fire. Fractures of brittle materials in complex stress fields are a particular problem which code-writers are grappling with. Improved software with helpful error messages is slowly reducing this type of problem.

\section{Where are we heading?}

It has been shown that there are many difficult assumptions which have to be made when doing a prediction of structural fire behaviour. These include the fire size, the fire location, sprinkler reliability, changes in use of the building. Additional unknowns are the possibility of fire after earthquake, and terrorist attacks. The use of quantitative risk assessment can help with these uncertainties.

Huge developments have occurred in the computational power of fire science and structural engineering, but both of these need to be used by experts. The two disciplines of combustion science and structural engineering are miles apart, so two groups of experts will always be needed. For this reason it would be very foolish to rush towards coupling of fire models with structural models. Any such coupling would lead to a "black box" mentality with a major decrease in our ability to make accurate predictions of structural fire behaviour.

Fire engineers and structural engineers need to talk to each other much more than they do now, and each group needs to learn as much as possible of the other discipline. These two topics are too big and too different for us to educate combined specialists in both disciplines. The area of intersection shown in Figure 3 is sometimes almost non-existent. The more the overlap the better between the two disciplines, but it is impossible for any one person to fill all of both circles and the intersecting area. 


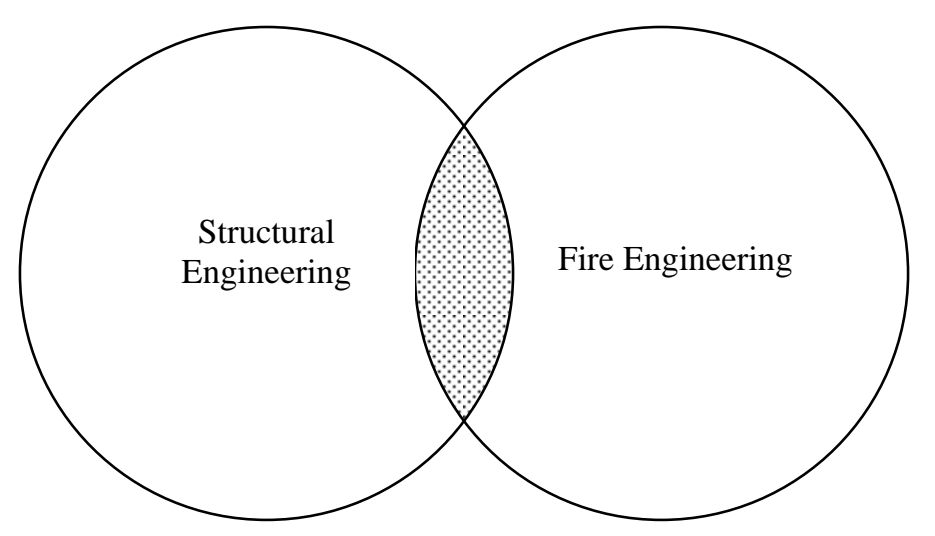

Fig. 3. Intersection between structural engineering and fire engineering

The fire research community needs to work on problems that can be solved, such as computer friendliness, clever data management, material properties, more test data, thermal analysis, and much better structural analysis, but always being aware of maintaining consistent crudeness.

\section{CONCLUSIONS}

- Structural engineering for fire safety has made huge advances in recent years.

- Normal structural engineering under ambient conditions is very challenging, and the addition of fire exposure makes the job even more difficult, with a large number of uncertainties.

- Computer analysis of fires and computer analysis of structures are both growing fast. Users of complex computer programs must consider the sensitivity of the input data and other assumptions on the accuracy of their results.

- New knowledge is needed about material properties at high temperatures, structural behaviour in severe fires, and the severity of expected fires, all supported by realistic fire test results for calibration and verification of design models.

- Quantitative risk assessment for structural fire safety will add a new dimension to solve some of the more difficult problems.

- Education and training is of paramount importance if we are going to provide fire engineers and structural engineers with the tools to talk to each other.

- The more advanced the computational tools become, the more we need to maintain a consistent level of crudeness, and rely on expert engineering judgement to come up with practical real-world solutions.

\section{REFERENCES}

[1] Stroup D.W. and Bryner N.P. (2007) Structural Collapse Research at NIST. Building and Fire Research Laboratory, National Institute of Standards and Technology. http://fire.nist.gov/bfrlpubs/fire07/PDF/f07084.pdf

[2] Milke, J. (2008). Performance-based Analysis Methods for Structural Fire Protection. Submitted to Fire Technology.

[3] Buchanan, A.H. (2001). Structural Design for Fire Safety. John Wiley \& Sons, UK.

[4] Franssen, J-M. (2005). Structures in Fire, Yesterday, Today and Tomorrow. Fire Safety Science, 8:21-35. doi:10.3801/IAFSS.FSS.8-21. 
[5] Chang J. (2008). Computer Simulation of Hollowcore Concrete Flooring Systems Exposed to Fire. $\mathrm{PhD}$ thesis. University of Canterbury, New Zealand.

http://www.civil.canterbury.ac.nz/fire/fe_resrch_reps.shtml

[6] NIST (2005). Collapse of the World Trade Center Towers. Final Report Federal Building and Fire Safety Investigation of the World Trade Center Disaster, NIST NCSTAR 1; 298 p. September 2005. National Institute of Standards and Technology, Gaithersburg, MD, 2005. http://fire.nist.gov/bfrlpubs/fire05/art119.html

[7] Elms D.G. (1992). "Consistent crudeness in system construction" in B.H.V. Topping (Ed), Optimisation and Artificial Intelligence in Civil Engineering, Kluwer Academic Publishers, v.1, pp61-70.

[8] Hertz, K. (2005). Assessment of Performance-based Requirements for Structural Design. Fire Safety Science, 8: 315-325. doi:10.3801/IAFSS.FSS.8-315.

[9] Moss P.J., Dhakal R.P., Bong M.W., Buchanan A.H. (2008a). Design of Steel Portal Frame Buildings for Fire Safety. Submitted to Journal of Constructional Steel Research.

[10] Moss P.J., Buchanan A.H., Fragiacomo M., and Austruy C. (2008b). On the Design of Bolted Connections Subjected to Fire. Proceedings, SiF 08 Structures in Fire Conference, Singapore, May 2008. 